\title{
Quantitative Analysis of Ageing Condition of Insulating Paper Using Infrared Spectroscopy
}

\author{
R. Saldivar-Guerrero, ${ }^{1}$ E. N. Cabrera Álvarez, ${ }^{1}$ U. Leon-Silva, ${ }^{2}$ F. A. Lopez-Gonzalez, ${ }^{2}$ \\ F. Delgado Arroyo, ${ }^{2}$ H. Lara-Covarrubias, ${ }^{3}$ and R. Montes-Fernandez ${ }^{3}$ \\ ${ }^{1}$ Centro de Investigación en Química Aplicada, Blvd. Enrique Reyna Hermosillo 140, Col. San José de los Cerritos, \\ 25294 Saltillo, COAH, Mexico \\ ${ }^{2}$ Instituto de Investigaciones Electricas, Reforma 113, Col. Palmira, 62490 Cuernavaca, MOR, Mexico \\ ${ }^{3}$ Comision Federal de Electricidad (CFE), Substations Department, Don Manuelito No. 32, Col. Olivar de los Padres, \\ 01780 Ciudad de México, Mexico
}

Correspondence should be addressed to R. Saldivar-Guerrero; ruben.saldivar@ciqa.edu.mx

Received 25 May 2016; Revised 22 September 2016; Accepted 25 September 2016

Academic Editor: Luigi Nicolais

Copyright (C) 2016 R. Saldivar-Guerrero et al. This is an open access article distributed under the Creative Commons Attribution License, which permits unrestricted use, distribution, and reproduction in any medium, provided the original work is properly cited.

\begin{abstract}
Transformers are very expensive apparatuses and are vital to make the whole power system run normally. The failures in such apparatuses could leave them out of service, causing severe economic losses. The life of a transformer can be effectively determined by the life of the insulating paper. In the present work, we show an alternative diagnostic technique to determine the ageing condition of transformer paper by the use of FTIR spectroscopy and an empirical model. This method has the advantage of using a microsample that could be extracted from the transformer on-site. The proposed technique offers an approximation quantitative evaluation of the degree of polymerization of dielectric papers and could be used for transformer diagnosis and remaining life estimation.
\end{abstract}

\section{Introduction}

Currently, the lifetime of the power transformer is defined by the life of the winding insulating paper. Many international efforts have been made to evaluate the condition and remaining life of the paper using indirect measurements as the analysis of furaldehydes dissolved in the oil. There are some other laboratory techniques that are more accurate, such as mechanical or physicochemical testing of the insulating paper, which require obtaining a piece of sample to determine the ageing.

The degree of ageing is defined by the value of the degree of polymerization (DP) of the insulating paper, and it represents the polymer chain length of the cellulose. The DP decreases with degradation; a new insulating paper may have a degree of polymerization of 1000 or more, while a paper at the end of its life in a transformer reaches values as low as 200 . This effect is promoted by mechanical and thermal stresses or by chemical degradation with different compounds present in the transformer oil and is irreversible, where the most important degradation mechanism is by acid hydrolysis. Thus, the life of a transformer can be effectively determined by the life of insulating paper [1] in order to prevent failure and prolong the useful life. Traditionally, furanic derivatives in oil have been correlated with the degree of polymerization of the paper, which has led to the establishment of transformer diagnosis based on dissolved gas analysis (DGA) in oil. An increase in the concentration of furan corresponds to the decrease of the tensile strength and the DP of the paper. The DP value obtained by this method tends to overestimate the remaining life of the transformer. This is because the 2 -furfural (2FAL) concentration that is obtained from the insulating oil is the average of all ageing rates, at various winding block positions, and is not a value from the hot spot or from the most aged spot. The degree of inaccuracy will also depend mostly on the external factors 
that have influenced the concentration of the main furan component, 2FAL, for example, oil replacement.

On the other hand, the viscometric test method ASTM D4243 used to measure the average degree of polymerization of insulation paper is a direct method to evaluate the deterioration level in power transformers. However, using this method is complicated and expensive due to the necessity of disassembling the transformer to get paper samples, which is made at the end of the transformer life, or after a failure.

An alternative diagnostic technique to determine the ageing condition of oil-paper insulation system could be by spectroscopy evaluation of the paper. Baird and coworkers [2] studied the water and oil content of insulating paper by UV-Vis spectroscopic and gravimetric water adsorption measurements. They demonstrated the use of a portable wide-wavelength spectrometer and multivariate statistical analysis to accurately measure nondestructively the water and oil content and DP estimation of insulating paper on the exposed windings of detanked transformers.

Arshad and Islam [3] analyzed the UV spectrum of the oil, qualitatively and quantitatively, with respect to the contamination present in it and interpreted dielectric response of insulation system. They found that the technique may prove to be an alternative to oil conductivity assessment. It also dictates the insulation system condition due to normal as well as accelerated deterioration/ageing.

In another study, Abu-Siada et al. [4] estimated the remaining life of a power transformer using UV-Vis spectroscopy and novel fuzzy logic approach. Results showed that there is a good correlation between oil spectral response and its furan contents; consequently, correlation between transformer ageing and UV trend can be easily established.

dos Santos and coworkers [5] developed a simple alternative method based on NIR spectroscopy combined with partial least squares regression to determine the degree of polymerization (DP) in transformer insulating papers.

Martins and coworkers [6] proposed an innovative approach to date fiber-based gelatin silver prints using nearinfrared spectroscopy (NIR) and multivariate analysis.

Rodriguez-Celis et al. [7] studied the insulating paper by analysis of the chemical markers of cellulose degradation dissolved in oil. Methanol, a marker that is intimately linked to the rupturing of 1,4- $\beta$-glycosidic bonds of cellulose, has been observed together with ethanol during laboratory ageing experiments. In this work, thermal degradation by pyrolysis was coupled with gas chromatography/mass spectrometry to assess the volatile byproducts generated at high temperatures with emphasis on methanol/ethanol generation.

Recently, Somekawa and coworkers [8] studied the concentration of furfural in transformer oils as an indicator for decomposition of insulating paper, using laser Raman spectroscopy. Furfural was characterized by Raman signal at $\sim 1707 \mathrm{~cm}^{-1}$, where no spectral interferences caused by oil-derived Raman signals occur. The results show that laser Raman spectroscopy is a useful alternative method for transformer health diagnosis.

In the present paper, an alternative technique is used to estimate the degree polymerization of microsamples of insulating paper ( $2 \mathrm{mg}$ weight approx.) by FTIR spectra. This
TABLE 1: Ageing processes for different types of kraft paper.

\begin{tabular}{ll}
\hline Kraft paper & Ageing process \\
\hline Dennison 22HCC $(0.076 \mathrm{~mm})$ & $\begin{array}{l}\text { In oxygen saturated mineral oil } \\
\text { at } 130^{\circ} \mathrm{C} \text {. Experiment time: } 912 \\
\text { hours. }\end{array}$ \\
Manning 220 $(0.063 \mathrm{~mm})$ & $\begin{array}{l}\text { Thermal ageing using an oven at } \\
124^{\circ} \mathrm{C} \text {. Experiment time: } 110\end{array}$ \\
\hline Dennison 22HCC $(0.076 \mathrm{~mm}$ hours. \\
Manning 220 $(0.063 \mathrm{~mm})$ & \\
\hline $\begin{array}{l}\text { Dennison 22HCC } 1 / 2 \\
(0.076 \mathrm{~mm})\end{array}$ & $\begin{array}{l}\text { In oxygen saturated mineral oil } \\
\text { Manning 220 }(0.063 \mathrm{~mm})\end{array}$ \\
$\begin{array}{l}\text { Cottrell }(0.076 \mathrm{~mm}) \\
\text { Dennison } 42 \mathrm{HCC}(0.127 \mathrm{~mm})\end{array}$ & hours. Experiment time: 712 \\
$\begin{array}{l}\text { Dennison 22HCC } 3 / 4 \\
(0.076 \mathrm{~mm})\end{array}$ & \\
\hline
\end{tabular}

technique allows us to obtain the characteristic spectrum of paper, on which changes associated with ageing were used to obtain an empirical model based on its peak intensities to obtain the DP of dielectric paper. By this way, the proposed technique offers a quantitative analysis of ageing condition of insulating papers that can be used for transformer diagnosis and remaining life estimation.

\section{Materials and Methods}

A series of accelerated ageing tests were performed on thermally upgraded paper strips of cut from (A) Electrical Grade Creped Kraft Paper (Dennison), (B) Hemp/Kraft Paper "Insuldur" (Manning), and (C) Internally Creped Kraft Paper (Cottrell). Accelerated ageing processes as well as type of kraft paper used in each one are shown in Table 1.

Fourier transform infrared (FTIR) spectrometer Equinox 55 from Bruker Corporation using the transmission cell was employed to determine changes in the structure of the aged kraft paper.

Sample preparation of dielectric paper aged in oil involves degreasing with benzene and solvent evaporation in air at room temperature. $1 \mathrm{~g}$ of dry paper samples free of oil was cut into small pieces $1-2 \mathrm{~mm}^{2}$ with scissors and milled using a cutting mill with a sieve insert of mesh 60. Milled paper was kept in controlled humidity atmosphere before evaluation.

For measuring the degree of polymerization by the viscometric method, $25 \mathrm{mg}$ of milled paper sample was put in a narrow-necked $150 \mathrm{~mL}$ Erlenmeyer flask and $22.5 \mathrm{~mL}$ of distilled water was added. The solution was shaken by hand to disintegrate and wet all the paper completely. Then, $22.5 \mathrm{~mL}$ of $1 \mathrm{M}$ solution of cupriethylenediamine was added, and the paper sample was magnetically stirred for at least 3 hours until the paper was completely dissolved. The solution so obtained was allowed to stand for $1 \mathrm{hr}$ at $20^{\circ} \mathrm{C} \pm 0.1^{\circ} \mathrm{C}$. Thereafter, the solution was transferred to the Ostwald viscometer reservoir for measuring. For each sample, three evaluations are made and DP calculation was done according to ASTM D4243-99 (2004).

For FTIR evaluations, a quantity of 1-2 mg of milled paper is weighed and mixed with $98 \mathrm{mg}$ of dry potassium bromide 


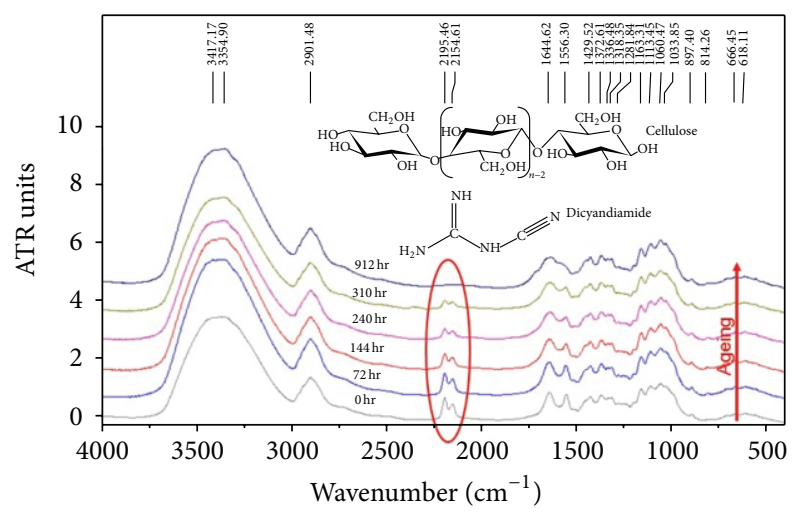

FIGURE 1: FTIR spectra of kraft paper samples with different ageing time.

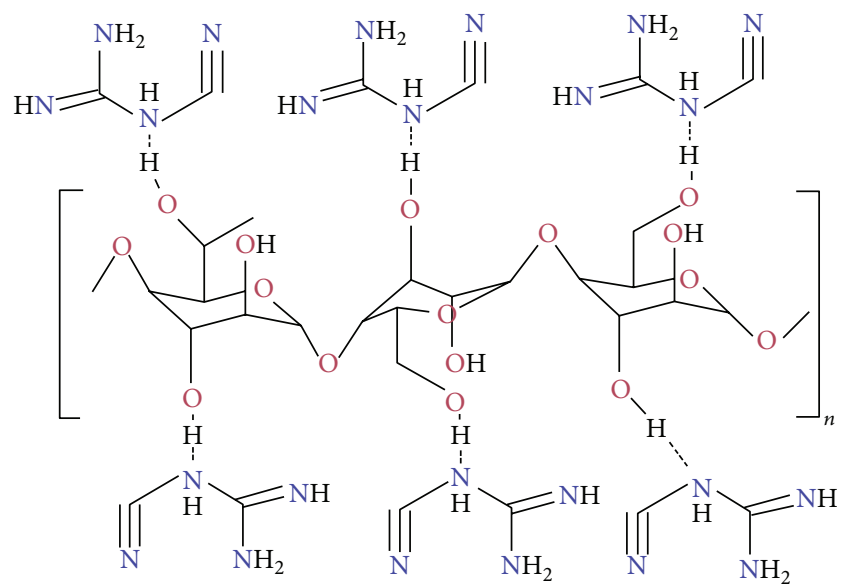

FIgURE 2: Dicyandiamide molecules linked to cellulose molecule.

$(\mathrm{KBr})$. The mixture is pressed at $6-8$ tons for 15 minutes so as to obtain a transparent disc which is set for evaluation in the transmission cell of FTIR spectrometer.

\section{Results and Discussion}

Figure 1 shows the FTIR spectra of Dennison 22HCC samples aged in oxygen saturated mineral oil at $130^{\circ} \mathrm{C}$ for different ageing times. Here, the cellulose molecule can be identified by the bands in $2901-3417 \mathrm{~cm}^{-1}$ due to C-H and O-H stretching vibrations; peaks in $1429 \mathrm{~cm}^{-1}$ and $1372 \mathrm{~cm}^{-1}$ corresponding to $\mathrm{CH}_{2}$ symmetric bending and $\mathrm{CH}$ bending, respectively; and bands in $1000-1200 \mathrm{~cm}^{-1}$ due to C-C stretching and C$\mathrm{OH}$ deformation vibrations.

Absorption peaks in 2195 and $2154 \mathrm{~cm}^{-1}$ have been identified as stretching of the $\mathrm{C} \equiv \mathrm{N}$ group and peaks in 1644 and $1556 \mathrm{~cm}^{-1}$ as $\mathrm{NH}_{2}$ and $\mathrm{NH}$ bending. This suggests the presence of a nitrogen-based compound like dicyandiamide $\mathrm{H}_{2} \mathrm{NC}(=\mathrm{NH})(\mathrm{NHCN})$, commonly used to make dielectric paper thermally upgraded [9]. This compound is linked to the cellulose molecule according to Figure 2.

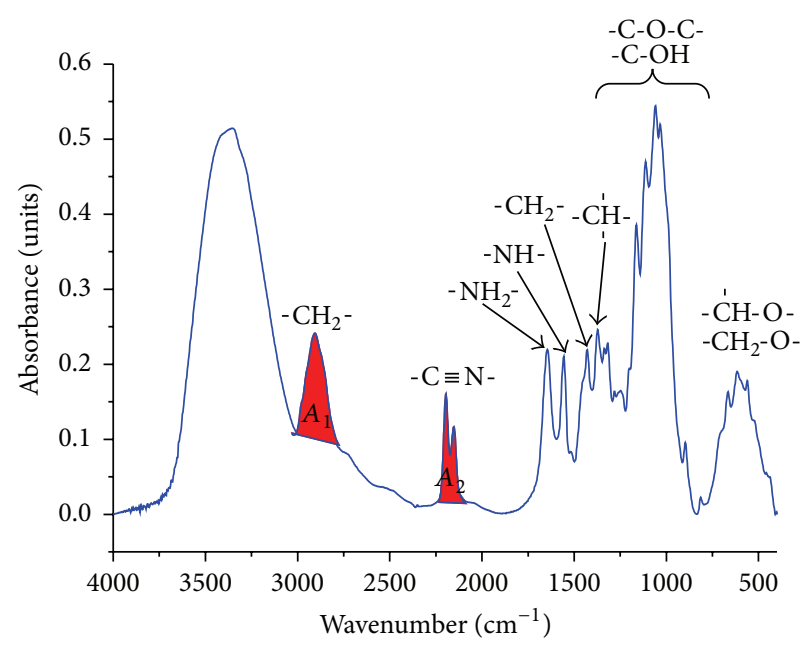

Figure 3: Defined areas $A_{1}$ and $A_{2}$ corresponding to $-\mathrm{CH}_{2}$ - and $\mathrm{C} \equiv \mathrm{N}$ absorption bands, respectively.

In Figure 1, we can observe that the well-defined absorption bands at $1556 \mathrm{~cm}^{-1}$ and $1644 \mathrm{~cm}^{-1}$ become broader as the paper ages. Also, the coupled bands between 2154 and $2195 \mathrm{~cm}^{-1}$ have lower intensity with ageing time, because as the cellulose paper degrades the glycosidic rings are broken and gradually lose glucose molecules linked with two molecules of dicyandiamide. As we mentioned above, these absorption peaks correspond to $\mathrm{C} \equiv \mathrm{N}$ nitrile group of the dicyandiamide. Taking advantage of this spectroscopy phenomenon, we correlated intensity of nitrile absorption peaks to the degree of polymerization (DP) of the kraft paper by the relation of areas $N$ :

$$
N=\frac{A_{1}}{A_{2}}
$$

where $A_{1}$ and $A_{2}$ correspond to the areas under the curve for $-\mathrm{CH}_{2}-$ and $\mathrm{C} \equiv \mathrm{N}$ absorption peaks, respectively, as is shown in Figure 3.

The value of $N$ relates the area of the nitrile group peak, $A_{2}$, to the area of - $\mathrm{CH}_{2}$ - group, $A_{1}$, which does not change as the DP of the paper changes, as it is shown in Figures 1 and 3. This is important because peaks intensity of the whole FTIR spectrum could change depending on sample preparation.

The value of $N$ is normalized according to

$$
\bar{N}=N_{t}-N_{0},
$$

where $N_{t}$ is the value of $N$ at ageing time $t$ and $N_{0}$ is the value of $N$ at $t=0$. By this way, we get a series of data relating DP and normalized peak intensity $\bar{N}$ as it is shown in Figure 4 . Here, we include the data obtained by different experiments mentioned in Table 1; all DP measurements were made by the viscometric method. 


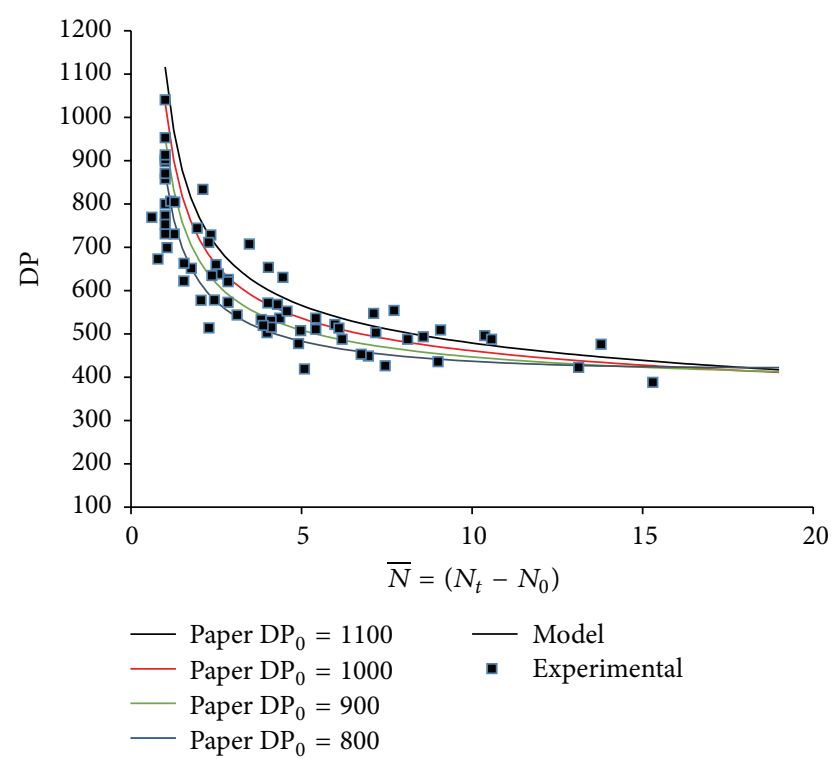

Figure 4: Experimental data of DP versus $\bar{N}$ and model according to (3).

As can be seen, DP decreases asymptotically as $\bar{N}$ increases and can be fitted according to the following equation:

$$
\begin{aligned}
\mathrm{DP}= & \frac{\mathrm{DP}_{0}}{2[\bar{N}]^{0.42 /(\bar{N}+0.3)}}+\frac{\mathrm{DP}_{0}}{200 e^{(\bar{N}+1 / \bar{N})}}+\frac{\mathrm{DP}_{0}}{3 \bar{N}}+\bar{N} A \\
& +200, \\
A= & 2 \times 10^{-5} \mathrm{DP}_{0}{ }^{2}-0.05 \mathrm{DP}_{0}+28,
\end{aligned}
$$

where $\mathrm{DP}_{0}$ is the degree of polymerization of the new paper, or the value of the paper when the transformer begins operation. Lines in red in Figure 4 correspond to fitted data according to (3) using $\mathrm{DP}_{0}$ values in the range of 800 and 1100. It is expected that a new paper with higher $\mathrm{DP}_{0}$ value will show higher $\bar{N}$ value due to higher peak intensity of the $\mathrm{C} \equiv \mathrm{N}$ nitrile group.

This empirical model has only two variables: the first one depends on the nitrile intensity peaks of the corresponding FTIR spectra of the paper $\bar{N}$ and the other one corresponds to the degree of polymerization of the paper at the beginning of operation of the transformer, $\mathrm{DP}_{0}$. A value of 1000 for $\mathrm{DP}_{0}$ can be used when there is no sample of the new paper, or when it is not known.

Because the ageing of the paper is measured by the degree of polymerization independently of the way in which it has been aged, (3) can be applied not only to evaluate DP for dielectric paper to be used in a new transformer winding, but also to follow up the performance of the paper during operation. This method has the advantage of using an amount of approximately $2 \mathrm{mg}$ of paper sample. FTIR technique has also the advantage that it is a fast evaluation technique and does not require a complicated sample preparation.

In order to validate (3), a series of DP measurements on different points of a transformer coil were made. Figure 5

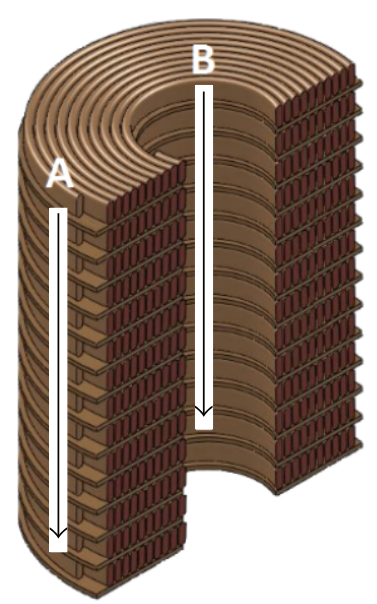

FIGURE 5: Schematic figure of a transformer winding showing points $\mathrm{A}$ and $\mathrm{B}$ where paper samples were taken for DP evaluation.

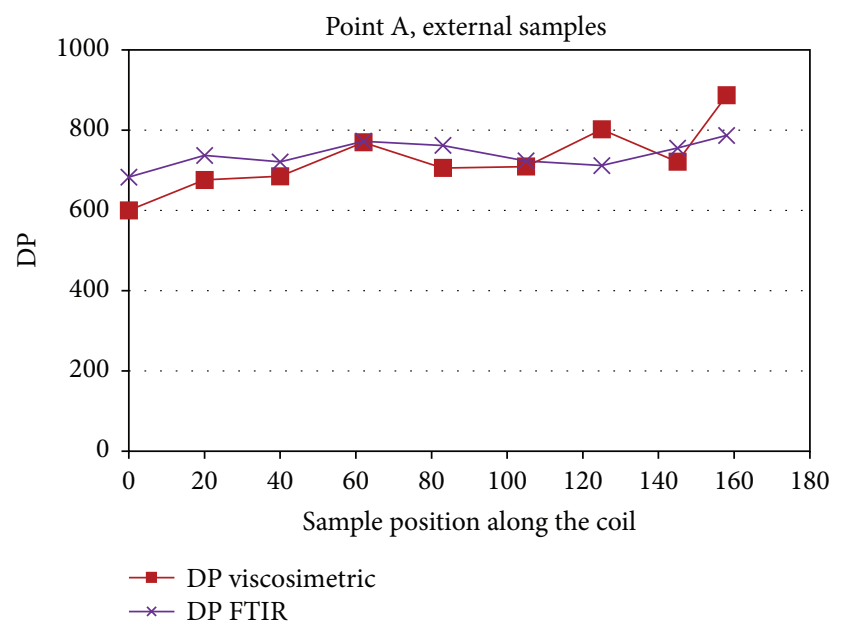

FIGURE 6: DP measurements of samples on point A of the transformer coil.

shows two lines where samples of paper were taken on external point $\mathrm{A}$ and internal point $\mathrm{B}$.

DP of the samples taken from the transformer coil was evaluated by viscometric method and compared with DP values obtained by (3) using FTIR spectra. Figures 6 and 7 show the DP values for paper samples along points A and B, respectively. The $x$-axis corresponds to the winding number where a sample was taken along each point of the coil.

According to DP measurements, we can observe that FTIR evaluations are close to the viscometric results, which validates the method proposed. Thus, this new procedure can be used to identify ageing condition of insulating paper by the degree of polymerization measurements using infrared spectroscopy. Furthermore, it has the advantage of using a very small sample and its evaluation by FTIR is quite easy. By this way, this new method can be used to follow up ageing of power transformers and power reactors and perform diagnostics of the equipment because it is well known that 


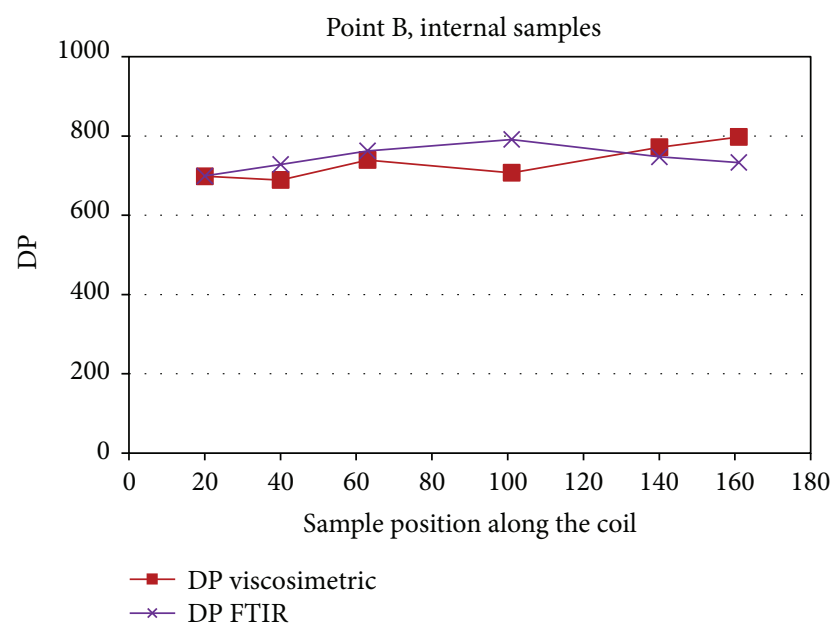

FIGURE 7: DP measurements of samples on point B of the transformer coil.

the lifetime of the equipment is defined by the life of the insulating paper.

\section{Conclusion}

A new method for evaluating ageing condition of insulating paper has been developed. Infrared spectroscopy has been used to measure the degree of polymerization correlating the absorption peaks of nitrogen-based compounds impregnated to the cellulose molecules. Data were fitted by an empirical model and were validated by a series of measurements comparing viscometric results with FTIR evaluations. The proposed technique offers an approximation quantitative evaluation of the degree of polymerization of dielectric papers and could be used for transformer diagnosis and remaining life estimation.

\section{Competing Interests}

The authors declare that they have no competing interests.

\section{References}

[1] M. F. Ariffin and P. S. Ghosh, "Estimating the age of paper insulation in $33 / 11 \mathrm{kV}$ distribution power Transformers using mathematical modelling," in Proceedings of the CIRED 19th International Conference on Electricity Distribution, Paper 0784, Vienna, Austria, May 2007.

[2] P. J. Baird, H. Herman, G. C. Stevens, and P. N. Jarman, "Nondestructive measurement of the degradation of transformer insulating paper," IEEE Transactions on Dielectrics and Electrical Insulation, vol. 13, no. 2, pp. 309-318, 2006.

[3] M. Arshad and S. M. Islam, "Power transformer condition assessment using oil UV-spectrophotometry," in Proceedings of the 2007 Annual Report-Conference on Electrical Insulation and Dielectric Phenomena (CEIDP '07), pp. 611-614, Québec, Canada, October 2007.

[4] A. Abu-Siada, L. Sin Pin, and S. Islam, "Remnant life estimation of power transformer using oil UV-Vis spectral response," in
Proceedings of the IEEE/PES Power Systems Conference and Exposition (PSCE '09), pp. 1-5, Seattle, Wash, USA, March 2009.

[5] E. O. dos Santos, A. M. S. Silva, W. D. Fragoso, C. Pasquini, and M. F. Pimentel, "Determination of degree of polymerization of insulating paper using near infrared spectroscopy and multivariate calibration," Vibrational Spectroscopy, vol. 52, no. 2, pp. 154-157, 2010.

[6] A. Martins, L. A. Daffner, A. Fenech, C. McGlinchey, and M. Strlič, "Non-destructive dating of fiber-based gelatin silver prints using near-infrared spectroscopy and multivariate analysis," Analytical and Bioanalytical Chemistry, vol. 402, no. 4, pp. 1459-1469, 2012.

[7] E. M. Rodriguez-Celis, S. Duchesne, J. Jalbert, and M. Ryadi, "Understanding ethanol versus methanol formation from insulating paper in power transformers," Cellulose, vol. 22, no. 5, pp. 3225-3236, 2015.

[8] T. Somekawa, M. Fujita, Y. Izawa, M. Kasaoka, and Y. Nagano, "Furfural analysis in transformer oils using laser raman spectroscopy," IEEE Transactions on Dielectrics and Electrical Insulation, vol. 22, no. 1, pp. 229-231, 2015.

[9] R. M. Morais, W. A. Mannheimer, M. Carballeira, and J. C. Noualhaguet, "Furfural analysis for assessing degradation of thermally upgraded papers in transformer insulation," IEEE Transactions on Dielectrics and Electrical Insulation, vol. 6, no. 2, pp. 159-163, 1999. 

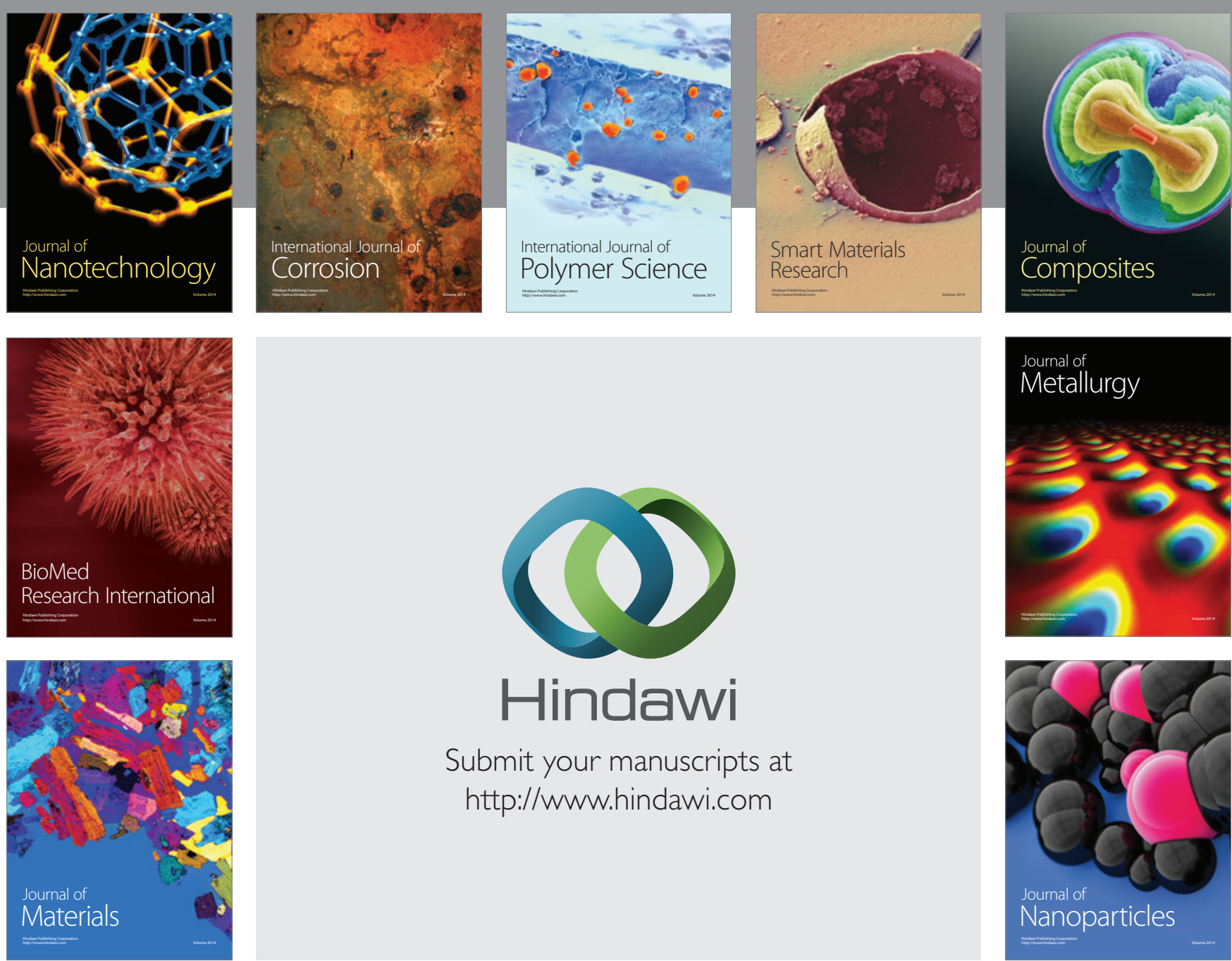

\section{Hindawi}

Submit your manuscripts at

http://www.hindawi.com

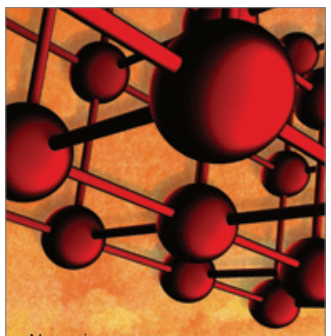

Materials Science and Engineering
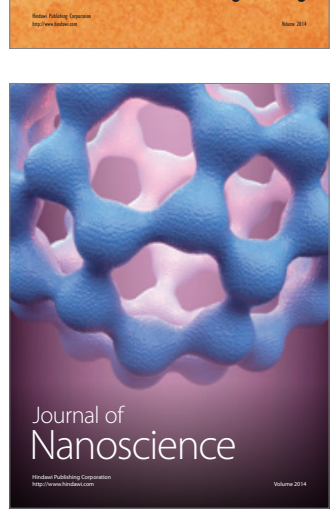
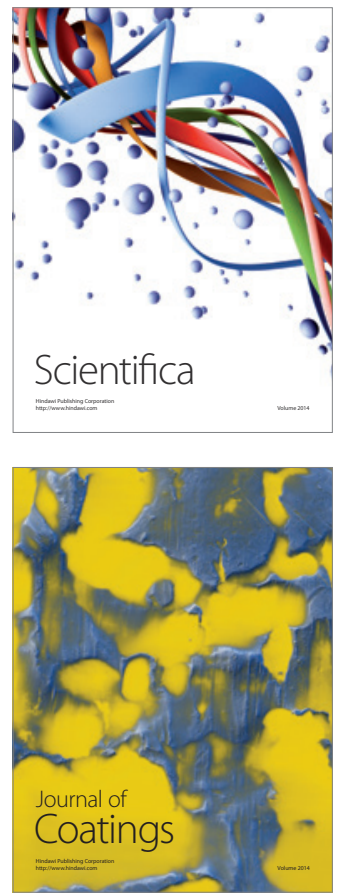
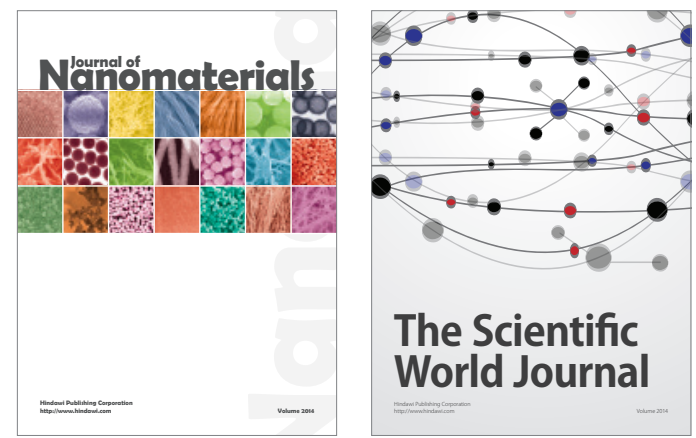

The Scientific World Journal
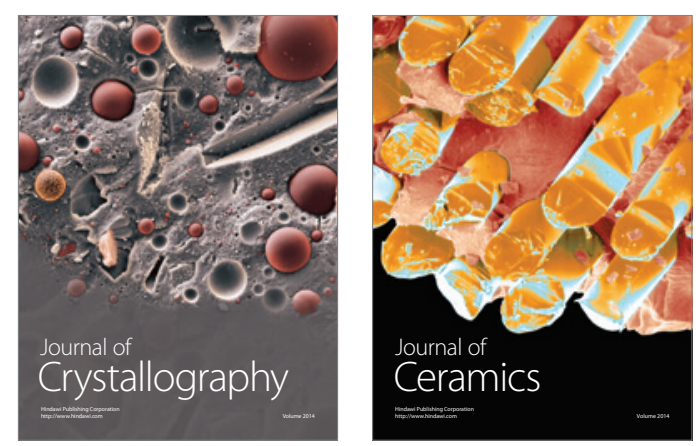
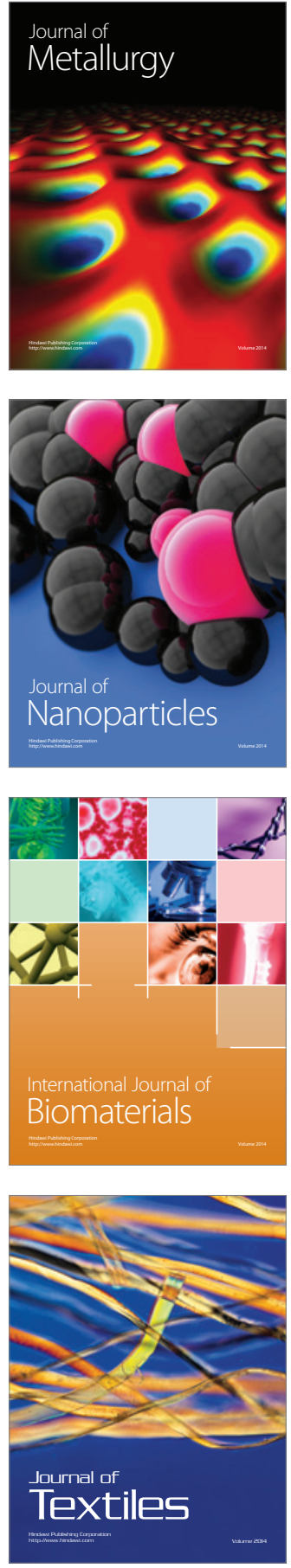